Case Report

\title{
Gastrointestinal Pyogenic Granuloma (Lobular Capillary Hemangioma): An Underrecognized Entity Causing Iron Deficiency Anemia
}

\author{
Marshall W. Meeks, ${ }^{1}$ Umar M. Kamal, ${ }^{1}$ Muhammad B. Hammami, ${ }^{2}$ Jason R. Taylor, \\ M. Louay Omran, ${ }^{2}$ Yongxin Chen, ${ }^{1}$ and Jin-Ping Lai ${ }^{1}$ \\ ${ }^{1}$ Department of Pathology, Saint Louis University School of Medicine, Saint Louis, MO 63104, USA \\ ${ }^{2}$ Department of Gastroenterology and Hepatology, Saint Louis University School of Medicine, Saint Louis, MO 63104, USA \\ Correspondence should be addressed to Marshall W. Meeks; meeks@slu.edu and Jin-Ping Lai; jinpinglai@slu.edu
}

Received 13 February 2016; Revised 19 May 2016; Accepted 22 May 2016

Academic Editor: Stephanie Van Biervliet

Copyright (C) 2016 Marshall W. Meeks et al. This is an open access article distributed under the Creative Commons Attribution License, which permits unrestricted use, distribution, and reproduction in any medium, provided the original work is properly cited.

\begin{abstract}
Pyogenic granuloma (PG), more accurately known as lobular capillary hemangioma, is a benign vascular tumor that usually occurs in the skin or oral mucosa. This lesion is rarely reported in the gastrointestinal tract but is known to bleed if not resected. We herein describe a case series with the clinical, endoscopic, and histologic findings of four cases of gastrointestinal PG at our institution. In addition, we provide a review of the literature and summation of all reported cases of PG specific to the gastrointestinal tract. Based on our experience, we suggest that the actual incidence of gastrointestinal PG may in fact be higher than reported because PG can be unrecognized or improperly diagnosed. It is important for the clinician to properly recognize this lesion as a source of anemia and its propensity to bleed during biopsy or resection.
\end{abstract}

\section{Introduction}

Pyogenic granuloma (PG), or more accurately known as lobular capillary hemangioma, is a benign vascular tumor characterized as bright red papules with a friable surface that may bleed profusely from minor trauma. PG typically affects the skin and oral mucosa, but a few cases have been reported in the gastrointestinal (GI) tract [1]. Given this lesion's vascular structure, severe anemia can develop if not recognized and correctly treated [2].

In this case series, we report four new cases of PG in the GI tract. Two patients with gastric PGs presented with melena and symptomatic anemia and were successfully treated with endoscopic polypectomy. A third patient presented with a PG with no stigmata of recent bleeding. The last patient was incidentally found to have a PG at the site of perforated Meckel's diverticulum after a small bowel resection. Here, we discuss the endoscopic and pathologic findings of these cases in addition to a review of the literature.

\section{Case Reports}

Case 1. A 70-year-old Caucasian female with a past medical history significant for end-stage renal disease, ulcerative colitis (maintained on mesalamine), and cirrhosis complicated by portal hypertensive gastropathy presented to our institution for elective endoscopic resection of a gastric polyp. She presented to an outside hospital two months priorly with complaints of intermittent bloody stools, up to eight stools per day, as well as early satiety and fatigue. Her hemoglobin was $8.1 \mathrm{~g} / \mathrm{dL}$ (down from $9.6 \mathrm{~g} / \mathrm{dL}$ a month earlier), for which she received a transfusion. Outside hospital esophagogastroduodenoscopy (EGD) revealed a 40-millimeter gastric polyp (Figure 1(a)). Endoscopic mucosal resection was attempted but aborted due to bleeding. At our institution, the polyp was partially resected with a piecemeal technique using a hot snare after injection of epinephrine. Eight hemostatic clips were successfully placed over the polypectomy site to prevent further bleeding. Histology from the polyp revealed 


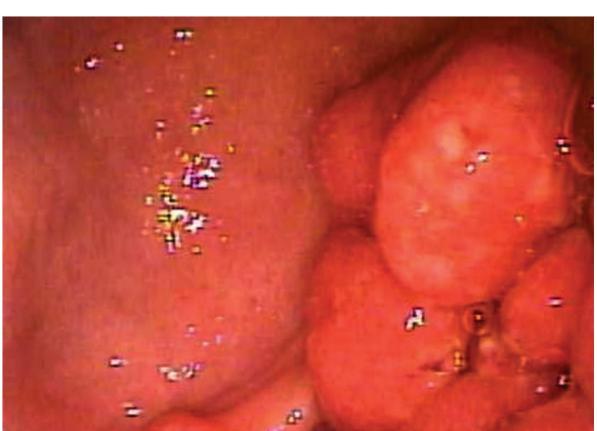

(a)

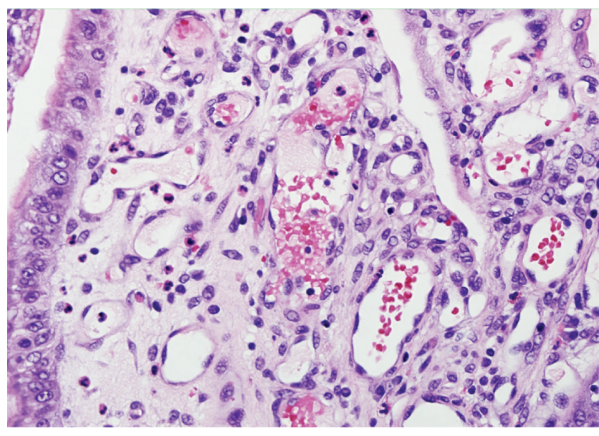

(c)

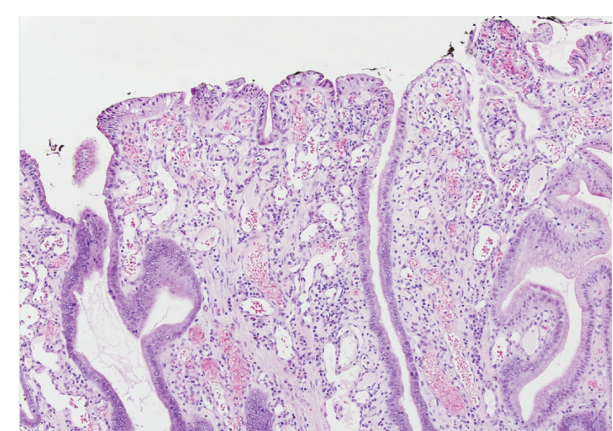

(b)

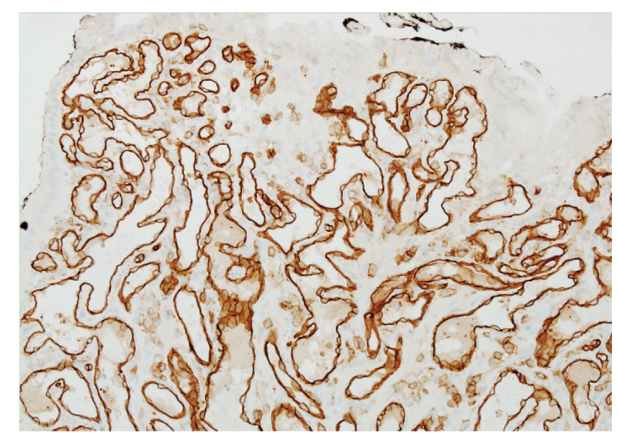

(d)

FIGURE 1: Pyogenic granuloma of the stomach (Case 1). (a) Endoscopic appearance of the $40 \mathrm{~mm}$ gastric polypoid nodule with surface erosion. (b-c) Histologically, a capillary hemangioma is present and arranged in a lobular pattern and filled with clusters of small capillary vessels ((b), $\times 100 ;(c), \times 400)$. (d) Immunohistochemistry of CD31 highlighting the capillary proliferation $(\times 400)$.

inflammatory and hyperplastic changes with features of lobulated capillary hemangioma and granulation tissue (Figures $1(b)-1(d))$.

Case 2. A 70-year-old Caucasian male was admitted for melena in the setting of dual antiplatelet therapy (DAPT). The patient had a medical history significant for end-stage renal disease secondary to chronic hypertension and coronary artery disease. He reported three black-tarry stools daily, starting eight days prior to admission. Coagulation profile was normal and presenting hemoglobin was $7.8 \mathrm{~g} / \mathrm{dL}$. EGD revealed a twelve-millimeter, oozing, and pedunculated polyp in the distal antrum with migration into the duodenal bulb (Figure 2(a)). Due to the DAPT, the polyp was only biopsied. In a subsequent endoscopy, the polyp was completely resected with a hot snare after injection with epinephrine. Three hemostatic clips were placed over the polypectomy site to prevent further bleeding. Histology from the initial biopsy and subsequent resection demonstrated fragments of foveolar hyperplasia and lobulated capillary hemangioma with focal granulation tissue, which is characteristic of PG (Figures 2(b)-2(d)). The capillaries were lined by single layer of cytologically bland endothelial cells. Neutrophils were frequently seen in the lesion. No Helicobacter pylori or other organisms were identified. Four months following PG resection, the patient's hemoglobin was stable and he denied any further episodes of melena.
Case 3. A 58-year-old Caucasian female with a medical history significant for nonalcoholic steatohepatitis (NASH) cirrhosis complicated by hepatic encephalopathy, ascites, banded and eradicated esophageal varices, gastric antral vascular ectasia (GAVE) treated on multiple occasions with radiofrequency ablation, and recurrent hospitalizations for melena and anemia presented to the emergency department for three days of melena and altered mental status. Coagulation profile was normal and her hemoglobin was $9.8 \mathrm{~g} / \mathrm{dL}$, essentially unchanged from her baseline. An EGD demonstrated small esophageal varices with no stigmata of bleeding, GAVE, and a normal duodenum. Focal radiofrequency ablation of GAVE was performed in the gastric antrum using the Halo-90 radiofrequency ablation catheter. Encephalopathy resolved with lactulose and she was discharged. An outpatient surveillance EGD one month later revealed a gastric antral papule with no stigmata of recent bleeding in addition to demonstrating the small esophageal varices and GAVE. Biopsies with a cold forceps of the gastric papule induced some bleeding that needed treatment with Argon Plasma Coagulation followed by clipping. Histological examination of the gastric papule was consistent with PG (Figures 3(a)$3(\mathrm{~b}))$.

Case 4. A 50-year-old African American female was admitted with abdominal pain and generalized abdominal distention. Her past medical history was notable for adult polycystic 


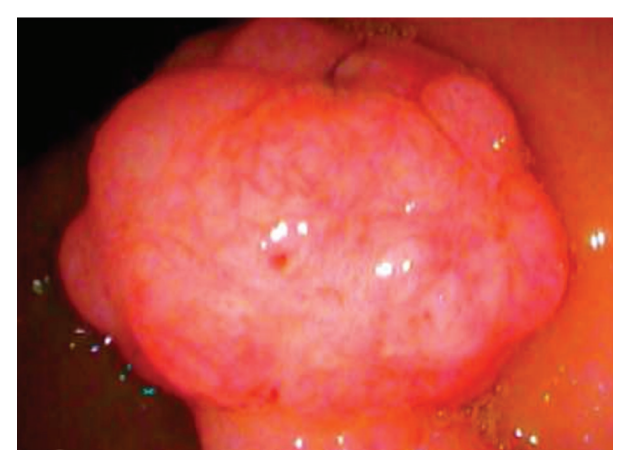

(a)

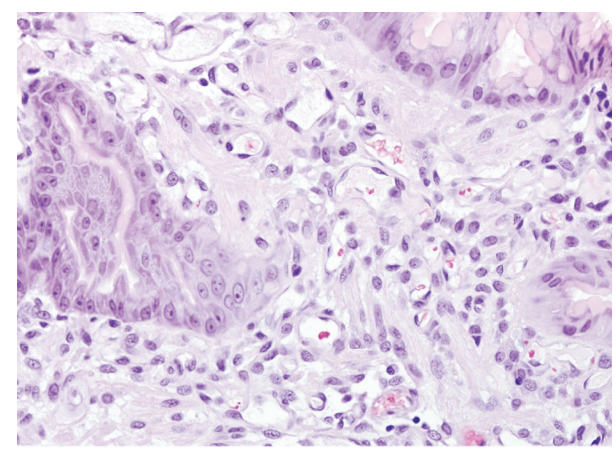

(c)

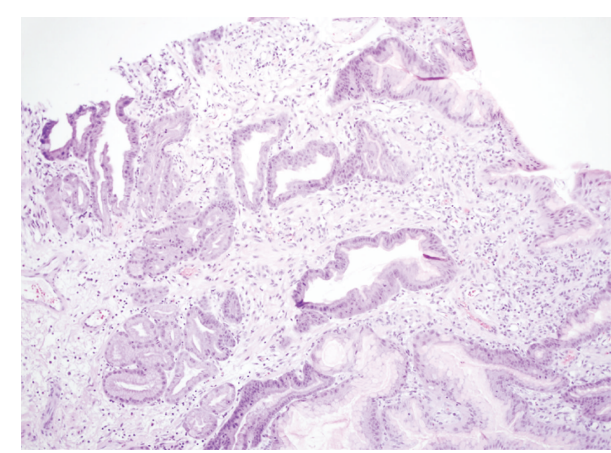

(b)

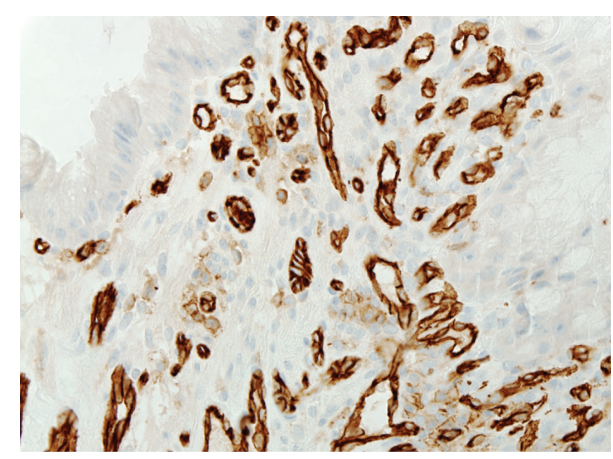

(d)

Figure 2: Pyogenic granuloma of the stomach (Case 2). (a) Endoscopic appearance of the $12 \mathrm{~mm}$ gastric polypoid nodule with surface erosions. (b-c) Histologically, a capillary hemangioma is present and arranged in a lobular pattern and filled with clusters of small capillary vessels and neutrophils infiltrate ((b), $\times 100 ;(c), \times 400)$. (d) Immunohistochemistry of CD31 highlighting the capillary proliferation $(\times 400)$.

liver. An exploratory laparotomy revealed a small bowel perforation. She then underwent a small bowel resection for perforated Meckel's diverticulum with primary small bowel anastomosis. Histological examination of the resected small bowel revealed an incidental finding of PG at the site of Meckel's diverticulum (Figures 3(c)-3(d)).

\section{Discussion}

PG of the gastrointestinal tract has the same histopathological features as those observed in the skin and oral mucosa, which are best described as a capillary hemangioma arranged in a lobular pattern and filled with clusters of small capillary vessels and a single layer of endothelial cells [2]. Granulation tissue and a neutrophilic infiltrate may also be present [3]. Given this, the main pathological differential diagnosis of PG includes bacillary angiomatosis (BA), Kaposi's sarcoma (KS), or inflammatory and/or hyperplastic polyps [4].

The histological pattern of BA is similar to PG because of the architectural pattern of endothelial cells, but BA can be distinguished by the Warthin-Starry stain. KS is characterized by a proliferation of blood vessels, inflammation, and spindle cells. Immunohistochemistry with antibodies against human herpesvirus- 8 can be used to distinguish this lesion from PG. Inflammatory polyps may also have neutrophilic infiltrates and granulation tissue, but they lack the characteristic capillary lobular arrangement of PG. Immunohistochemistry for
CD31 or CD34 can be used to identify endothelial cells and distinguish PG from inflammatory polyps.

While PG is rarely reported in the literature, the actual incidence is probably much higher. We have diagnosed four cases at our institution all within the past year (approximately $8 \%$ of all GI PG cases ever reported). Our speculation is that PG of the GI tract is a commonly unrecognized or misdiagnosed lesion. For instance, it may be incorrectly diagnosed as an inflammatory and/or hyperplastic polyp. This is problematic because that lesion is not a possible source of anemia as PG is.

The mechanism underlying PG pathogenesis is not well understood. As the name suggests, it previously was thought that PG arose from an infectious etiology. Most current theories at least partially involve PG arising from a reactive process against mucosal irritation, such as trauma. However, most patients do not report previous trauma at the site of PG [5], suggesting that another component is involved. For instance, hormonal influences could also play a role, as mucosal PG lesions are more likely to occur in pregnant women [6]. One other proposed precipitating factor is liver cirrhosis as it has been noted to be a common underlying disorder in some patients with GI PG [7, 8]. This association might be caused by retrograde dilatation of capillary blood vessels secondary to portal hypertension that causes venous stasis and leads to the growth of PG [8]. 


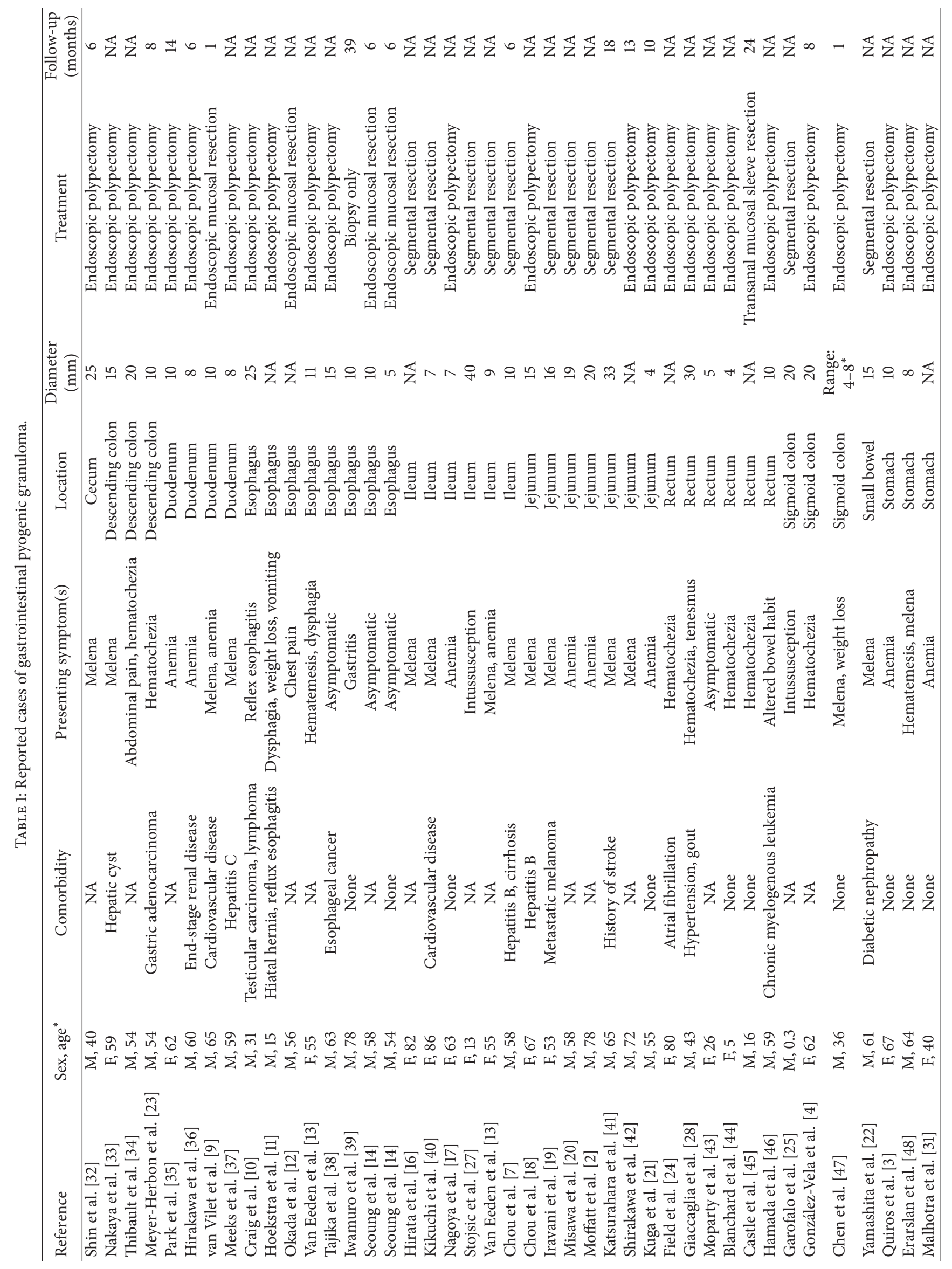




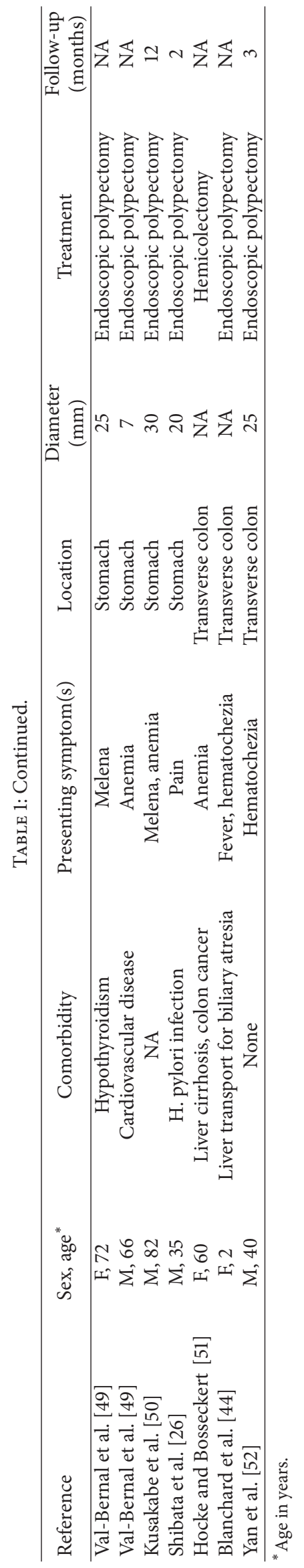




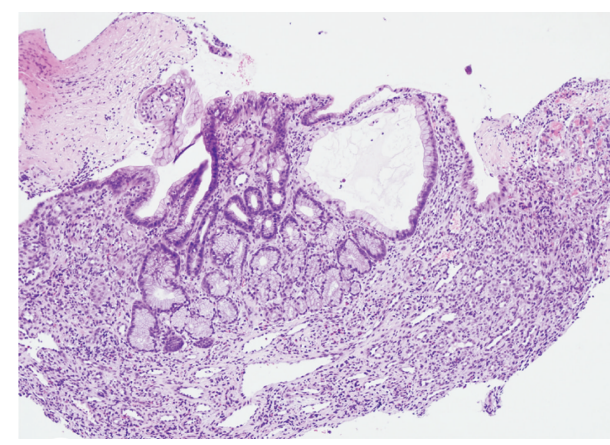

(a)

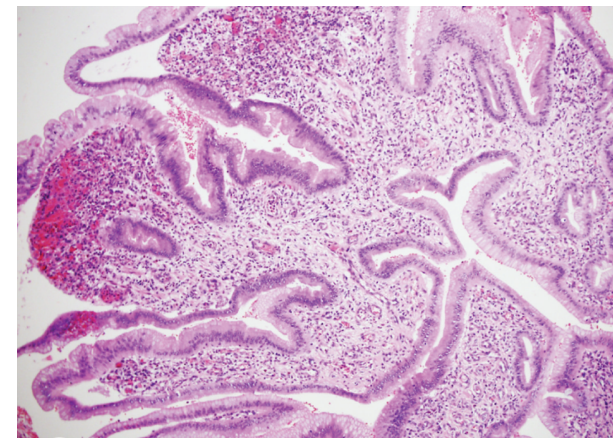

(c)

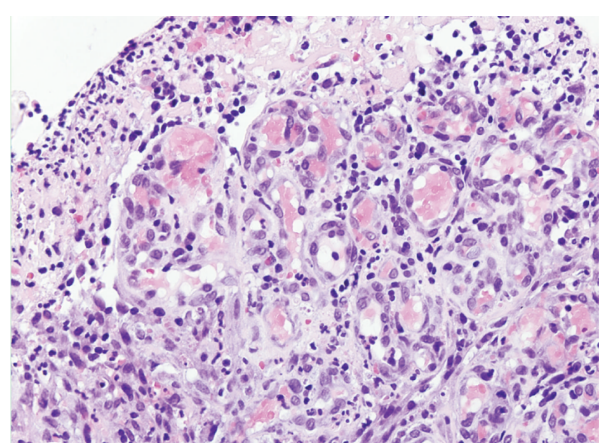

(b)

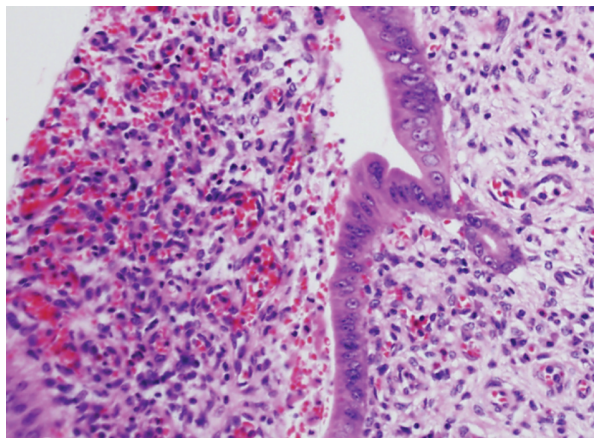

(d)

Figure 3: (a-b) Pyogenic granuloma of the stomach (Case 3). (c-d) Pyogenic granuloma of the ileum (Case 4). Low power views ((a) and (c), $\mathrm{H} \& \mathrm{E}, 100 \mathrm{x})$ reveal gastrointestinal mucosa with variable ulceration. High power ((b) and (d), H\&E, 400x) exhibits lobular arrangement of capillary proliferation and active inflammation.

There are approximately 50 cases of GI PG in the English literature indexed on MEDLINE (Table 1). The most commonly reported anatomical locations are the esophagus [915], small bowel [2, 16-22], and the colon [4, 23-25]. The most common clinical manifestation is anemia; 39 (79\%) patients presented with symptoms of bleeding. Initial hemoglobin values were reported for 17 patients; median hemoglobin was $8.1 \mathrm{~g} / \mathrm{dL}$ (range: $4-16.6 \mathrm{~g} / \mathrm{dL}$ ). Other presentations are rarely reported and depend on the anatomical location of the PG. For instance, esophageal lesions can present with dysphagia [13], stomach lesions as gastritis [26], small intestine lesions as intussusception [25, 27], or rectum lesions as tenesmus [28]. Four $(8 \%)$ patients were asymptomatic and their PG lesions were found incidentally.

The median age of patients at time of PG diagnosis was 59 years (range: $0.3-86$ years). $71 \%$ of patients were older than 50 when diagnosed with GI PG. However, there are reports of GI PG in the pediatric population [25,27]. Men seem to be more affected than women: $29(60 \%)$ of the patients were men and 19 (40\%) were women.

The endoscopic appearance of PG lesions is usually a smooth and ulcerated surface that appears friable. The color ranges from bluish-red to sanguine with a superficial white or opaque film covering. As with our third patient, they can grow quickly and then stabilize in size [29]. PG size was reported for 37 patients; median PG diameter was $15 \mathrm{~mm}$ (range: $4-33 \mathrm{~mm}$ ). Only 8 lesions (22\%) were larger than
$20 \mathrm{~mm}$. PG typically only involves the mucosa but can extend into the submucosa [13] and even the full thickness of the luminal wall [30].

Resection of PG lesions is necessary in patients with anemia, but postresection bleeding is a potential complication [31]. Resection is most commonly accomplished by endoscopic mucosal resection, endoscopic polypectomy, or surgical resection. Of those, endoscopic polypectomy was by far the most common treatment method. Regardless of treatment modality, recurrence is rare. Length of follow-up after PG resection was recorded for 19 patients, and only 2 (11\%) of those patients had recurrence after resection [23, 28]. However, median follow-up was only 8 months (range: 1-39 months).

In conclusion, PG of the GI tract is a very rarely reported clinical entity. However, the actual incidence may in fact be higher if this lesion is commonly unrecognized or improperly diagnosed as an inflammatory or hyperplastic polyp. It is important for the clinician to properly recognize PG as a source of anemia.

\section{Competing Interests}

The authors declare that there is no conflict of interests regarding the publication of this paper. 


\section{References}

[1] S. E. Mills, P. H. Cooper, and R. E. Fechner, "Lobular capillary hemangioma: the underlying lesion of pyogenic granuloma. A study of 73 cases from the oral and nasal mucous membranes," American Journal of Surgical Pathology, vol. 4, no. 5, pp. 471-479, 1980.

[2] D. C. Moffatt, P. Warwryko, and H. Singh, "Pyogenic granuloma: an unusual cause of massive gastrointestinal bleeding from the small bowel," Canadian Journal of Gastroenterology, vol. 23, no. 4, pp. 261-264, 2009.

[3] J. A. Quiros, J. Van Dam, T. Longacre, and S. Banerjee, "Gastric pyogenic granuloma," Gastroenterology and Hepatology, vol. 3, no. 11, pp. 850-854, 2007.

[4] M. C. González-Vela, J. F. Val-Bernal, M. F. Garijo, and C. García-Suárez, "Pyogenic granuloma of the sigmoid colon," Annals of Diagnostic Pathology, vol. 9, no. 2, pp. 106-109, 2005.

[5] S. J. Patrice, K. Wiss, and J. B. Mulliken, "Pyogenic granuloma (lobular capillary hemangioma): a clinicopathologic study of 178 cases," Pediatric Dermatology, vol. 8, no. 4, pp. 267-276, 1991.

[6] G. Kroumpouzos and L. M. Cohen, "Dermatoses of pregnancy," Journal of the American Academy of Dermatology, vol. 45, no. 1, pp. 1-22, 2001.

[7] J.-W. Chou, H.-C. Lai, and Y.-C. Lin, "Pyogenic granuloma of the small bowel diagnosed by capsule endoscopy and doubleballoon enteroscopy," Clinical Gastroenterology and Hepatology, vol. 7, no. 7, article A26, 2009.

[8] C. Lin, Y. Hsieh, C. Hsu et al., "Clinical and endoscopic features of gastric pyogenic granuloma," Advances in Digestive Medicine, vol. 1, no. 4, pp. 118-125, 2014.

[9] E. P. van Vliet, R. Arensman, and H. J. Pullens, "An unusual cause of bleeding from the duodenum: pyogenic granuloma," Journal of Gastrointestinal and Liver Diseases, vol. 24, no. 2, article 141, 2015.

[10] R. M. Craig, S. Carlson, H. A. Nordbrock, and H. Yokoo, "Pyogenic granuloma in Barrett's esophagus mimicking esophageal carcinoma," Gastroenterology, vol. 108, no. 6, pp. 1894-1896, 1995.

[11] E. R. Hoekstra, P. Fockens, and P. Scholten, "A 15-year-old boy with an esophageal pyogenic granuloma and subsequent Barrett's esophagus (with videos)," Gastrointestinal Endoscopy, vol. 65, no. 7, pp. 1086-1088, 2007.

[12] N. Okada, T. Matsumoto, K. Kurahara et al., "Pyogenic granuloma of the esophagus treated by endoscopic removal," Endoscopy, vol. 35, no. 4, p. 375, 2003.

[13] S. Van Eeden, G. J. A. Offerhaus, F. H. Morsink, B. P. Van Rees, O. R. C. Busch, and C. J. M. Van Noesel, "Pyogenic granuloma: an unrecognized cause of gastrointestinal bleeding," Virchows Archiv, vol. 444, no. 6, pp. 590-593, 2004.

[14] H. G. Seoung, G. H. Kim, G. A. Song et al., "Esophageal pyogenic granuloma: endosonographic findings and endoscopic treatments," Clinical Endoscopy, vol. 46, no. 1, pp. 81-84, 2013.

[15] T. Okumura, S. Tanoue, K. Chiba, and S. Tanaka, "Lobular capillary hemangioma of the esophagus. A case report and review of the literature," Acta Pathologica Japonica, vol. 33, no. 6, pp. 1303-1308, 1983.

[16] K. Hirata, N. Hosoe, H. Imaeda et al., "Obscure gastrointestinal bleeding: resection of a pyogenic granuloma of the ileum via double-balloon enteroscopy," Clinical Journal of Gastroenterology, vol. 7, no. 5, pp. 397-401, 2014.

[17] H. Nagoya, S. Tanaka, A. Tatsuguchi et al., "Rare cause of obscure gastrointestinal bleeding due to pyogenic granuloma in the ileum detected by capsule endoscopy and treated with double balloon endoscopy," Digestive Endoscopy, vol. 22, no. 1, pp. 71-73, 2010.

[18] J. W. Chou, S. F. Chen, C. Y. Yii, Y. S. Shih, K. S. Cheng, and H. W. Chang, "Jejunal pyogenic granuloma diagnosed and treated with spiral enteroscopy," Endoscopy, vol. 44, supplement 2, pp. E2-E3, 2012.

[19] A. Iravani, A. Law, M. Millward, M. Warner, and S. Sparrow, "Bleeding small intestine pyogenic granuloma on 18F-FDG PET/CT," Clinical Nuclear Medicine, vol. 40, no. 11, pp. 869-870, 2015.

[20] S.-I. Misawa, H. Sakamoto, A. Kurogochi et al., "Rare cause of severe anemia due to pyogenic granuloma in the jejunum," $B M C$ Gastroenterology, vol. 15, no. 1, article 126, 2015.

[21] R. Kuga, C. K. Furuya Jr., S. N. Fylyk, and P. Sakai, "Solitary pyogenic granuloma of the small bowel as the cause of obscure gastrointestinal bleeding," Endoscopy, vol. 41, supplement 2, pp. E76-E77, 2009.

[22] K. Yamashita, Y. Arimura, M. Saito et al., "Pyogenic granuloma of the small bowel," Endoscopy, vol. 45, supplement 2, pp. E9E10, 2013.

[23] P. Meyer-Herbon, C. Brugnolaro, R. Frei, and M. C. Sulz, "Pyogenic granuloma of the descending colon: a rare cause of lower gastrointestinal bleeding," ACG Case Reports Journal, vol. 2, no. 2, pp. 74-75, 2015.

[24] M. Field, N. Inston, U. Zanetto, and N. Cruikshank, "Pyogenic granuloma of the colon," International Journal of Colorectal Disease, vol. 22, no. 9, pp. 1139-1140, 2007.

[25] S. Garofalo, M. Mostert, I. Morra et al., "Pyogenic granuloma of the Sigmoid colon causing intussusception in an infant," APSP Journal of Case Reports, vol. 6, no. 2, article 15, 2015.

[26] T. Shibata, Y. Ichikawa, M. Okubo, T. Tahara, T. Ishizuka, and I. Hirata, "Gastric pyogenic granuloma detected due to abdominal symptoms and treated with endoscopic resection," Internal Medicine, vol. 52, no. 24, pp. 2749-2752, 2013.

[27] Z. Stojsic, D. Brasanac, G. Kokai et al., "Intestinal intussusception due to a pyogenic granuloma," Turkish Journal of Pediatrics, vol. 50, no. 6, pp. 600-603, 2008.

[28] V. Giaccaglia, A. Stefanuto, C. Cavallotti, A. Quintiliani, and F. Stipa, "Transanal excision of rectal pyogenic granuloma: case report and literature review," Surgical Laparoscopy, Endoscopy and Percutaneous Techniques, vol. 21, no. 2, pp. e91-e92, 2011.

[29] B. S. Chandra and P. N. Rao, "Two cases of giant pyogenic granuloma of scalp," Indian Dermatology Online Journal, vol. 4, no. 4, pp. 292-295, 2013.

[30] T. Yao, E. Nagai, T. Utsunomiya, and M. Tsuneyoshi, "An intestinal counterpart of pyogenic granuloma of the skin: a newly proposed entity," American Journal of Surgical Pathology, vol. 19, no. 9, pp. 1054-1060, 1995.

[31] A. Malhotra, S. Jaganmohan, and L. D. Scott, "Clinical challenges and images in GI," Gastroenterology, vol. 136, no. 4, pp. 1168-1463, 2009.

[32] C. J. Shin, S. G. Hong, and M. Lee, "A case of pyogenic granuloma of the cecum treated by endoscopic resection," Endoscopy, vol. 46, no. 1, pp. E277-E278, 2014.

[33] T. Nakaya, T. Tokunaga, S. Aono et al., "Pyogenic granuloma of the descending colon," Endoscopy, vol. 39, supplement 1, pp. E259-E260, 2007.

[34] A. Thibault, A. Lavergne-Slove, P. Soyer, V. Ozenne, P. Marteau, and X. Dray, "Pyogenic granuloma of the colon," Endoscopy, vol. 44, supplement 2, pp. E155-E156, 2012. 
[35] S.-Y. Park, C.-H. Park, W.-S. Lee, H.-S. Kim, S.-K. Choi, and J.-S. Rew, "Pyogenic granuloma of the duodenum treated successfully by endoscopic mucosal resection," Gut and Liver, vol. 3, no. 1, pp. 48-51, 2009.

[36] K. Hirakawa, K. Aoyagi, T. Yao, K. Hizawa, H. Kido, and M. Fujishima, "A case of pyogenic granuloma in the duodenum: successful treatment by endoscopic snare polypectomy," Gastrointestinal Endoscopy, vol. 47, no. 6, pp. 538-540, 1998.

[37] M. W. Meeks, M. B. Hammami, U. M. Kamal, M. L. Omran, J. R. Taylor, and J.-P. Lai, "Pyogenic granuloma of the duodenum," Journal of Gastroenterology and Hepatology, 2016.

[38] M. Tajika, T. Nakamura, H. Kawai et al., "Short-term development of esophageal pyogenic granuloma observed on endoscopy," Gastrointestinal Endoscopy, vol. 64, no. 2, pp. 269270, 2006.

[39] M. Iwamuro, H. Okada, T. Tanaka et al., "Morphological changes in a pyogenic granuloma of the esophagus observed over three years," Internal Medicine, vol. 54, no. 14, pp. 17371740, 2015.

[40] A. Kikuchi, T. Sujino, M. Yamaoka et al., "Pyogenic granuloma of the ileum diagnosed by double-balloon enteroscopy," Internal Medicine, vol. 53, no. 18, pp. 2057-2059, 2014.

[41] M. Katsurahara, T. Kitade, S. Tano et al., "Pyogenic granuloma in the small intestine: a rare cause of obscure gastrointestinal bleeding," Endoscopy, vol. 47, supplement 1, pp. E133-E134, 2015.

[42] K. Shirakawa, T. Nakamura, M. Endo, K. Suzuki, T. Fujimori, and A. Terano, "Pyogenic granuloma of the small intestine," Gastrointestinal Endoscopy, vol. 66, no. 4, pp. 827-828, 2007.

[43] B. Moparty, S.-Y. Xiao, and M. S. Bhutani, "Pyogenic granuloma presenting as a rectal polyp at the site of a previous polypectomy," Endoscopy, vol. 38, supplement 2, pp. E2-E3, 2006.

[44] S. S. Blanchard, G. Chelimsky, S. J. Czinn, R. Redline, and J. Splawski, "Pyogenic granuloma of the colon in children," Journal of Pediatric Gastroenterology and Nutrition, vol. 43, no. 1, pp. 119-121, 2006.

[45] S. L. Castle, B. J. Naik-Mathuria, A. L. Kawaguchi, and D. B. Shaul, "Management of rectal pyogenic granuloma with transanal mucosal sleeve resection," Journal of Pediatric Surgery, vol. 47, no. 9, pp. 1754-1756, 2012.

[46] Y. Hamada, K. Tanaka, S. Tano et al., "Pyogenic granuloma mimicking a colon cancer," Endoscopy, vol. 46, no. 1, pp. E153E154, 2014.

[47] T.-C. Chen, J.-M. Lien, K.-F. Ng, C.-J. Lin, Y.-P. Ho, and C.M. Chen, "Multiple pyogenic granulomas in sigmoid colon," Gastrointestinal Endoscopy, vol. 49, no. 2, pp. 257-259, 1999.

[48] E. Erarslan, F. Ekiz, H. Unverdi et al., "Unusual cause of acute gastrointestinal bleeding: gastric pyogenic granuloma," Digestive Endoscopy, vol. 24, no. 2, article 122, 2012.

[49] J. Val-Bernal, M. Mayorga, M. L. Cagigal, and J. CabezasGonzález, "Gastric pyogenic granuloma: report of two cases and review of the literature," Pathology-Research and Practice, vol. 212, no. 1, pp. 68-71, 2016.

[50] A. Kusakabe, H. Kato, K. Hayashi et al., "Pyogenic granuloma of the stomach successfully treated by endoscopic resection after transarterial embolization of the feeding artery," Journal of Gastroenterology, vol. 40, no. 5, pp. 530-535, 2005.

[51] M. Hocke and H. Bosseckert, "Incorrect macroscopic diagnosis of colonic carcinoma made at endoscopy," Endoscopy, vol. 36, no. 7, p. 668, 2004.

[52] S.-L. Yan, S.-F. Chen, C.-H. Chen, and Y.-H. Yeh, "Pyogenic granuloma of the transverse colon," Gastrointestinal Endoscopy, vol. 82, no. 4, pp. 761-763, 2015. 


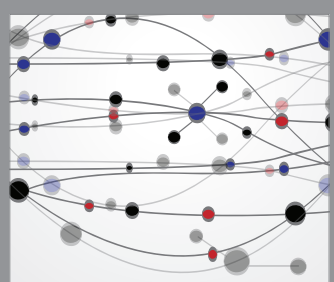

The Scientific World Journal
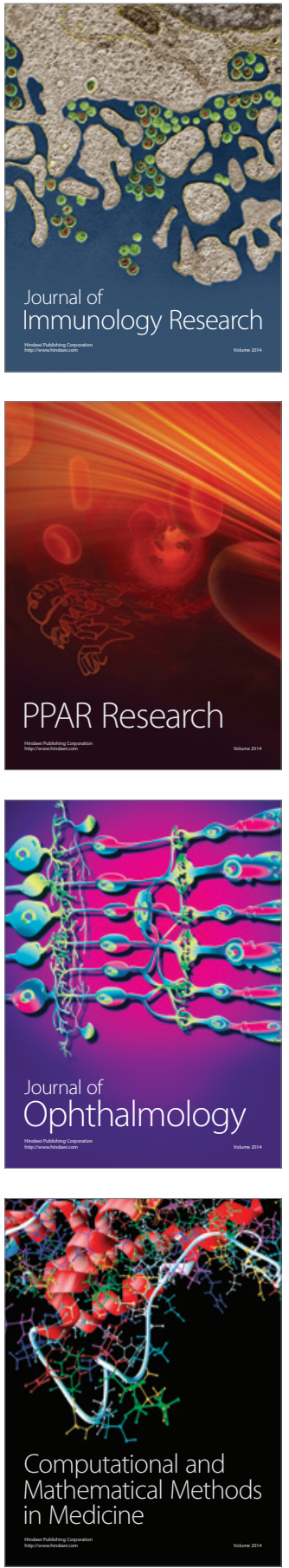

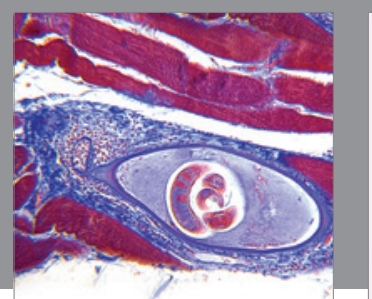

Gastroenterology Research and Practice

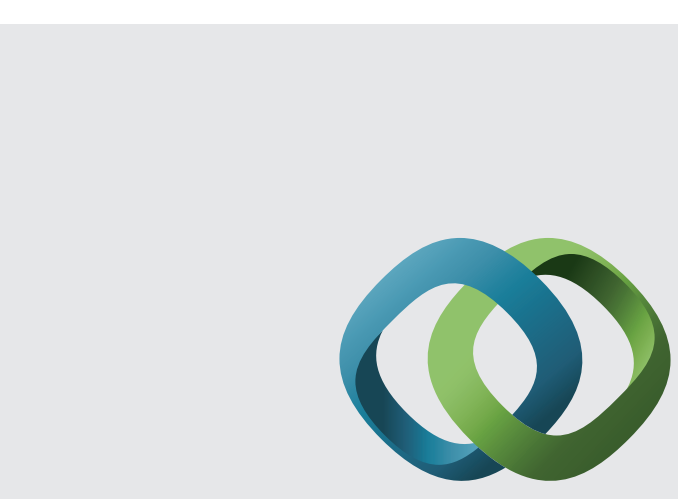

\section{Hindawi}

Submit your manuscripts at

http://www.hindawi.com
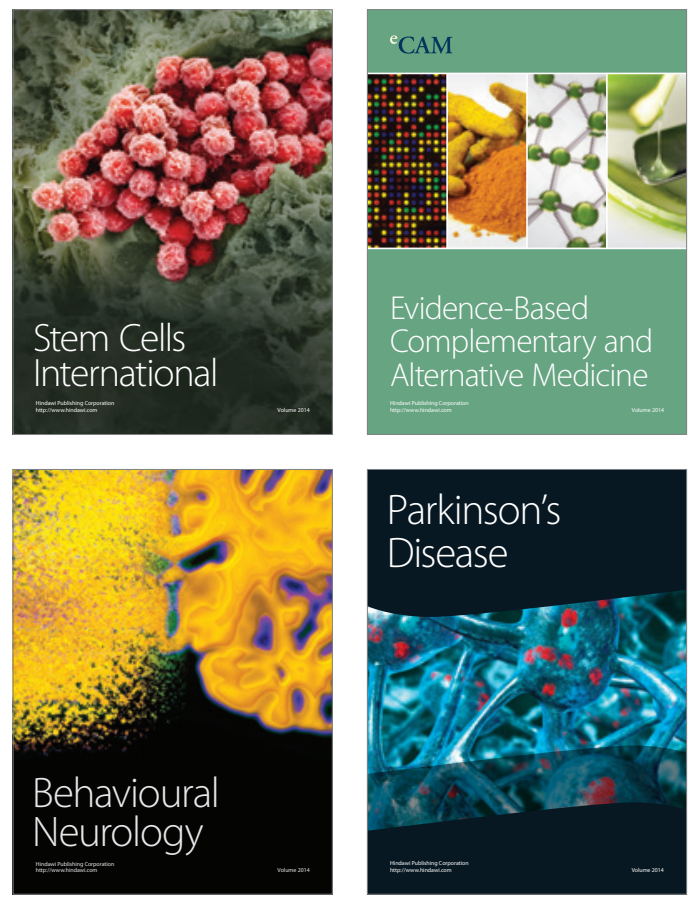
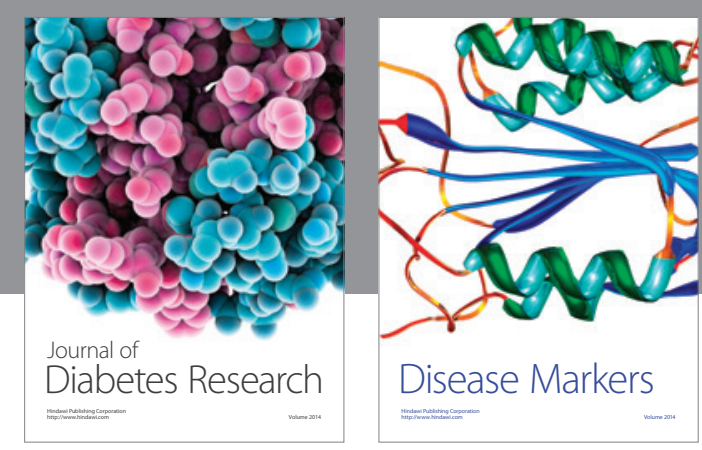

Disease Markers
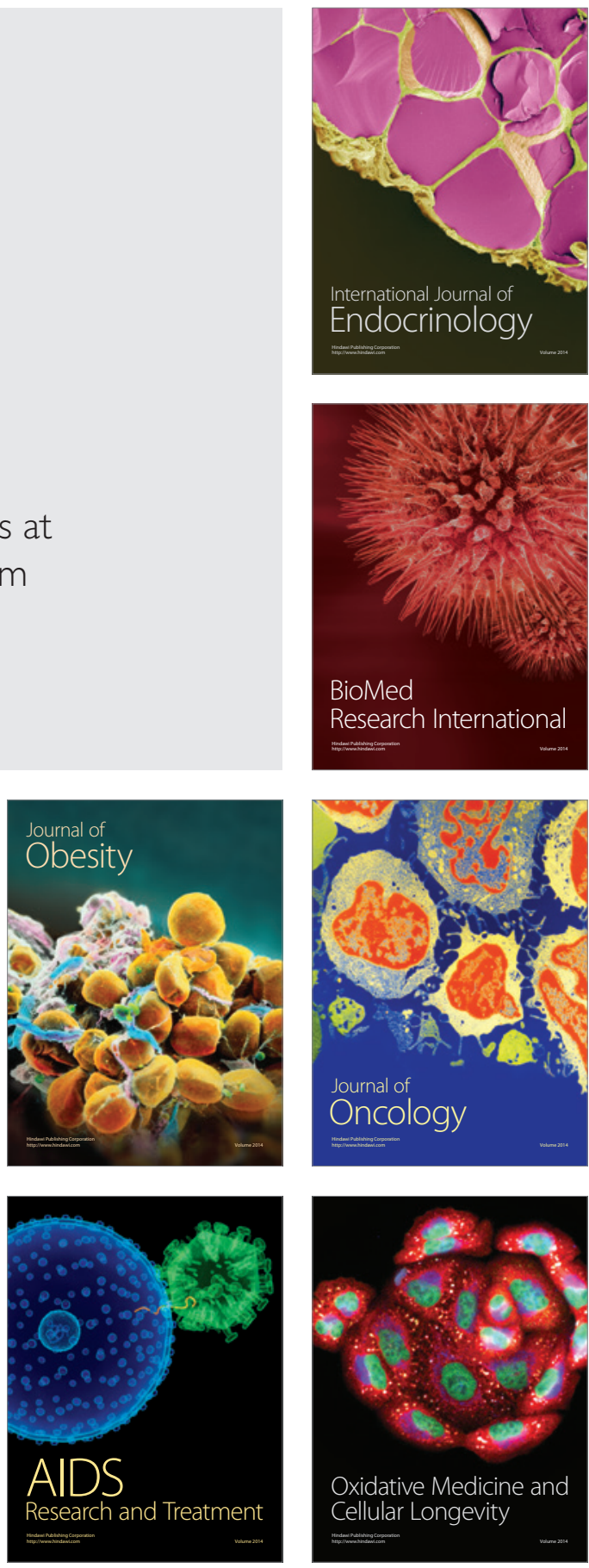